\title{
Computational Model for Microgeneration Simulation, From Solar and Wind Renewable Sources, With Optimal Allocation of Loads, Electric Vehicle and Energy Storage, In a Residential Electrical Micro Network
}

\author{
Wesley Thiago Egea Tiem *, Clodomiro Unsihuay-Vila ${ }^{1}$ \\ ${ }^{1}$ Universidade Federal do Paraná, Curitiba, Brasil.
}

\begin{abstract}
The electrical sector is under constant evolution. One of the areas refers to the consumers that come to be generators, implementing distributed generation, interconnected to a smart grid. This article discusses the improvement of an algorithm, already presented in the literature, to make the best temporal allocation of loads, electric vehicle, storage and many sources of generation, aiming at the maximum financial performance, that is, the lowest value for the energy invoice The modeling consists of a Mixed Integer Linear Programming (MILP) algorithm, which considers each component of the system and weighs the maintenance and shelf life of storage devices, basically batteries, loads that can be reallocated and the concept of Vehicle-to-grid, performing a daily analysis. The simulation has considered the hypothetical case of a residence, in which are included storage, electric vehicle and redistribution of loads, as well as wind and solar generation. Several scenarios are simulated, with or without the presence of some of the components. The results indicate that the simplest model, only redistributing the loads, can provide a sensible monetary savings of approximately 60\%, while with the application of all the components modeled, there can be a reduction in the invoice of $90 \%$.
\end{abstract}

Key words: Microgrid, microgeneration, distributed generation, wind energy, solar energy, load reallocation, storage, electric vehicle, smart grid.

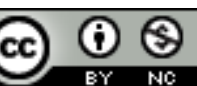

*Author of correspondence: wesleytiem@yahoo.com.br 


\section{INTRODUCTION}

The distributed microgeneration, integrated with smart grids is more and more engaged in the energetic scenario. A house that generates part of its own electricity, from renewable sources with low environmental impact, like solar or wind energy, can be listed as an example of this scenario [1][6].

Therefore, moved by a huge demand at rush hours, the hourly based differentiation of tariffs is common for industries and a real possibility for residences in a near future. In view of this, a load profile redistribution, aiming at the best utilization of locally generated energy and the most favorable tariffs, can contribute significantly to the financial result for residences, keeping its total consumption [1].

Basically, this work follows the steps, model and the theoretical reasoning presented by [1], which is not intended to be fully presented here. From this base model, a validation of the results obtained is considered and also the possibility to carry out some improvement at the algorithm in some aspects, allowing other sources of generation, apart from solar.

As far as temporal loads redistribution is concerned, it is interesting and maybe necessary to have some optimization algorithm, that can evaluate the better distribution and suggest when and how to use the loads that can have be manipulated, named as elastic loads. In addition, it is interesting that there is also an assessment of the financial return, to indicate the viability of the change in consumption and the implementation of renewable energy sources.

Thus, distribution networks are migrating to an active network profile, where the client can also be a generator in the system, and this model requires new forms of management and even tariffs.

Alongside, comes the possibility of integrating electric vehicles, which tends to be more present in the near future. The characteristic of this load is that, in general, the batteries are reload when it arrives at the residence and it is disconnected from the network during its period of use.

One feature of the electric vehicle is the existence of some internal storage device, which can be integrated and used as storage of the residence system as a whole [3-6].

Each renewable generation system follows a specific modeling that must be done from meteorological data or with the aid of specific software. Here, the solar generation profile in [1] is used and for wind generation the result presented in [2] is adopted for the city of Curitiba.

As for the loads, the normal daily usage has been taken into account, the times the loads are used and for how long, as well as which loads can be reallocated and at which time of day. The collection of these data is of paramount importance in order for the algorithm to be able to reorient consumption so that the user can continue performing the same daily activities while maintaining the same consumption, but taking advantage of the best tariff differences and storage devices.

The optimization algorithm in question is a Mixed Integer Linear Programming (MILP) algorithm, able to, from certain parameters and functions, adjust the variables to achieve specific objectives such as maximization or minimization of functions.

From the modeling proposed in [1] it is proposed an improvement in the sense of allowing the inclusion of more than one generation source, in this example wind generation; to evaluate the result of these together and also to verify the validity of the origin algorithm as to the functionality in the situation where the local generation is larger than the accumulated consumption, making adjustments, if necessary 


\section{OBJECTIVES}

Thus, this work aims to:

Implement an algorithm capable of proposing the distribution of variable loads and storage devices, as well as electric vehicle, using hourly basis during the day, in facilities that have their own generation, connected at variable rates on an hourly basis;

Evaluate the operation of the proposed algorithm in several scenarios, more specifically the financial impacts of the redistribution of load and use of storage and generation devices, among the diversity of scenarios and to evaluate the non-existence of generation or the scenario where the accumulated generation is greater than consumption.

\section{METHODS}

The development consisted of an extensive bibliographical research, followed by the actual implementation of a proper model, based on [1], able to perform the functionalities proposed in the objective.

In the bibliographic research, in addition to the identification of load characteristics, the study of renewable matrices and intelligent networks, the possible optimization models through Linear Mixed Iterative Programming (PLIM) were assessed and able to solve the problem of load distribution in time. In this research, the model proposed by [1] was adopted, on which tests and changes were made to meet the objectives.

According to this model, the objective is to minimize a MILP objective function, which ponders the weight of the redistribution of the load with the storage. This model proposed in [1] uses as denominator the number of optimal cycles and the optimal cost, that is the smallest value for each of the plots without applying any constraint. This serves as a beacon for the occurrence of a better convergence during the execution of the algorithm.

However, in the original model, when the optimal cost is calculated, in the scenario where the accumulated generation is greater than the consumption, the optimal cost becomes negative, which in turn goes to the denominator of the minimization function, which implies a not convergence, making the value to be minimized (costs) reach the highest possible value. Given this failure found in the adopted model, the equation (1) of [1] was modified so that it actually performed its function, according to (1) below, taking the module of the optimal cost objective function.

$$
\left(\lambda^{\text {costs }} \frac{F_{o b j}^{\text {costs }}}{F_{o b j}^{\text {costs.optimal }}}+\lambda^{\text {cycles }} \frac{F_{o b j}^{\text {cycles }}}{F_{o b j}^{\text {cyles.optimal }}}\right)
$$

With this improved algorithm, several scenarios were tested, varying the generation profile, diversity of sources, load diversity, storage devices and electric vehicle, validating the results of the algorithm and its usefulness.

Another alteration was in the form of parameterizing the local generation within the algorithm. The original model treats only solar generation. In this work a change is made, also considering wind generation that was simulated externally on hourly basis for the period of one day. The evaluated generation, then, is the sum of the generations coming from both sources: Solar and Wind. 


\section{RESULTS AND DISCUSSION}

As mentioned, the MILP parameterization proposed by [1] was adopted, with the changes already mentioned above. And for the test and validation, the same data were assumed and proposed, that is, a fictitious residence, a set of solar generation in the city of Curitiba, an electric vehicle and a storage system, with all the necessary parameters for the simulation, such as performance, capacity or power, besides the inclusion of the wind power generation system

The algorithm considers that some loads do not have flexibility of use for temporal reallocation, as in the case of illumination. On the other hand, some loads can be reallocated to moments where the applied tariff is smaller or there is greater generation from the sources of distributed generation and storage devices such as washing machines, showers, irons or hair dryers.

The data used for each of the simulations are presented graphically, both the generation and consumption profile in each of the scenarios, starting from the base case, where there is no change in consumption, ie the consumption profile considered natural in the residence and advancing in each of the other proposed case studies, as presented below.

In Figure 1 we have the generation curve adopted for each of the considered sources and the sum of the two. The solar generation data were obtained from [1] and for wind turbine the information of [2], which presents the hourly generation for a typical day in Curitiba, of a wind turbine of nominal capacity of $0.5 \mathrm{~kW}$ installed in the studied place.

Figure 1- Solar and wind generation profile.

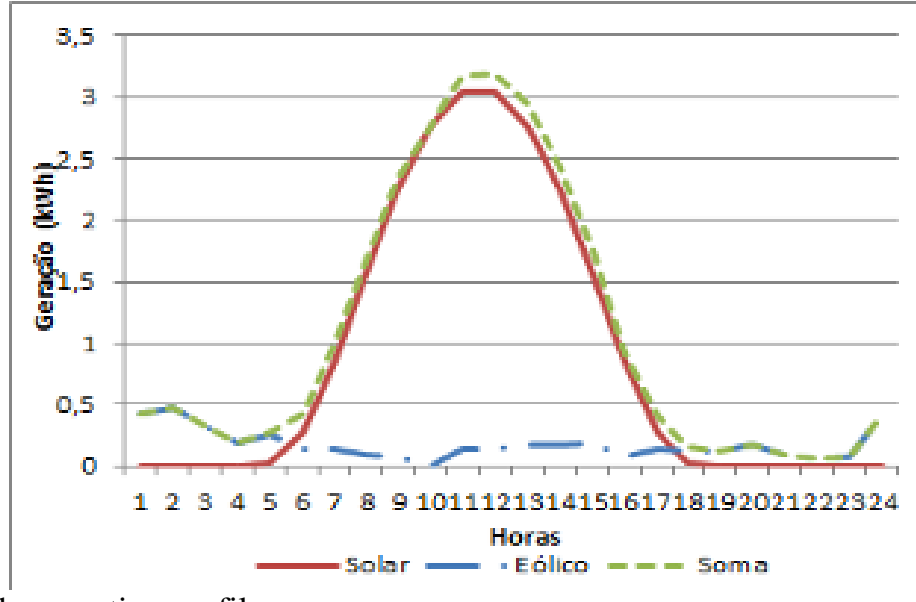

Source: The authors based on references [1] and [2].

Figure 2 shows the estimates of daily consumption used in the simulation, with respect to elastic loads (which can be redistributed) and inelastic. It also shows the presence and consumption of an electric vehicle, which can be used as an external storage device. In this basic scenario the load redistribution algorithm was also applied, aiming at a lower value in the invoice, considering null storage and generation in the premise.

A consumption peak can be observed precisely at the time when the tariff is higher, it is therefore inferred, that even without the inclusion of generation it would be possible to significantly reduce the invoice only by redistributing the load, which is a parameter of comparison of the effect of the insertion of generation in the system or of storage systems together with the redistribution of consumption. 


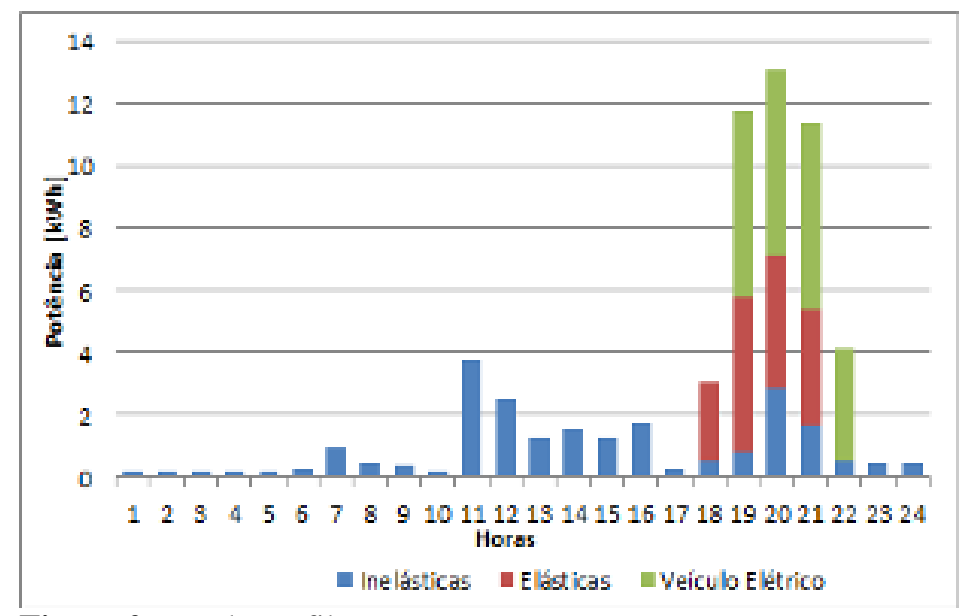

Figure 2- Loads profile.

Source: The author based on reference [1].

The results of the generation insertion together with the temporal redistribution of consumption and electric vehicle, related to solar generation (Case 1), wind (Case 2) or both (Case 3) are presented in Figures 3, 4 and 5 respectively.

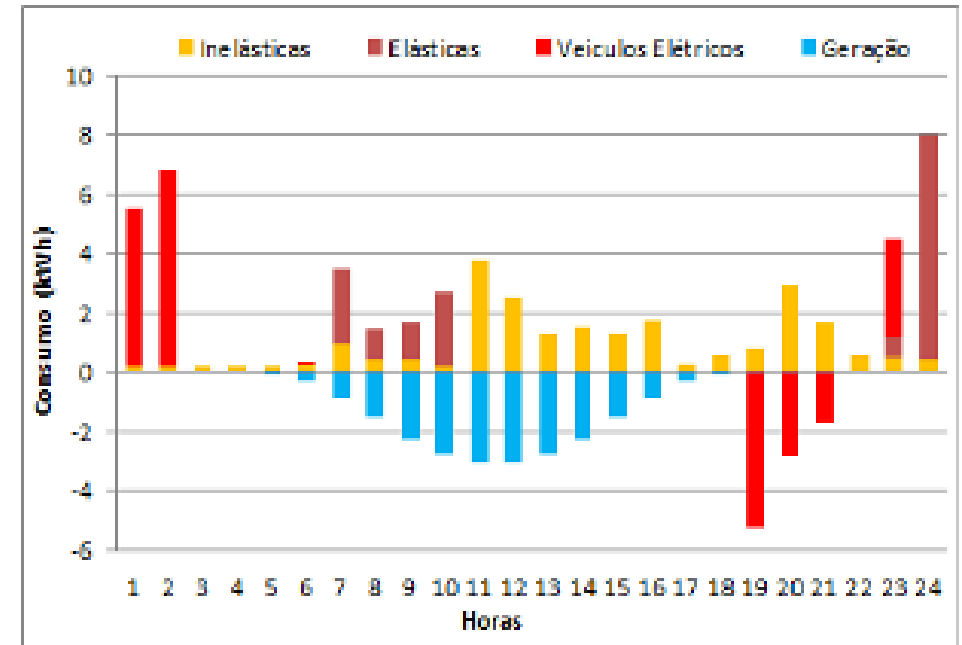

Figure 3 - Solar generation plus consumption redistribution.

Source: The authors.

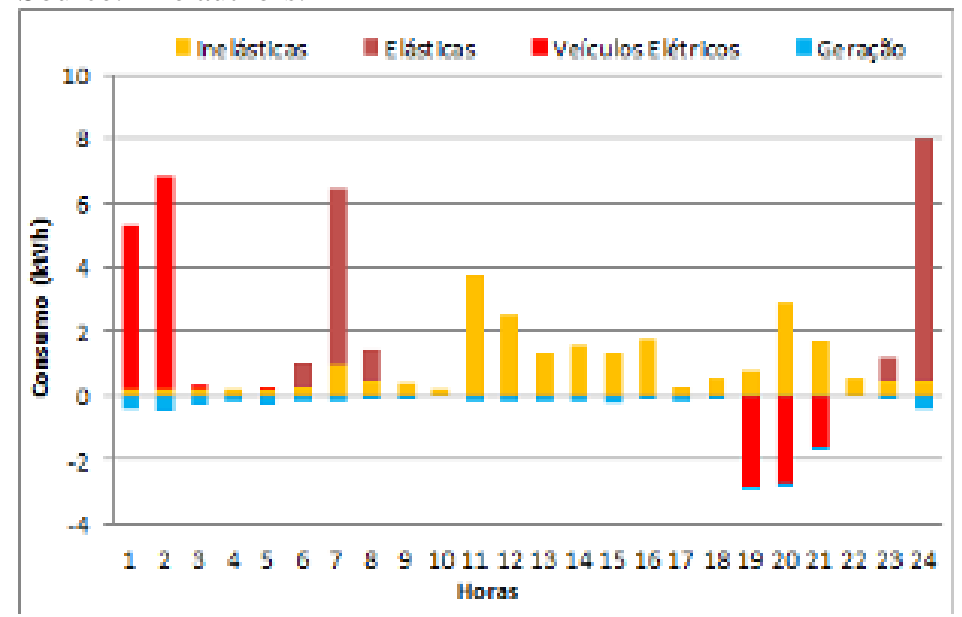

Figure 4 - Wind generation plus consumption redistribution.

Source: The authors. 


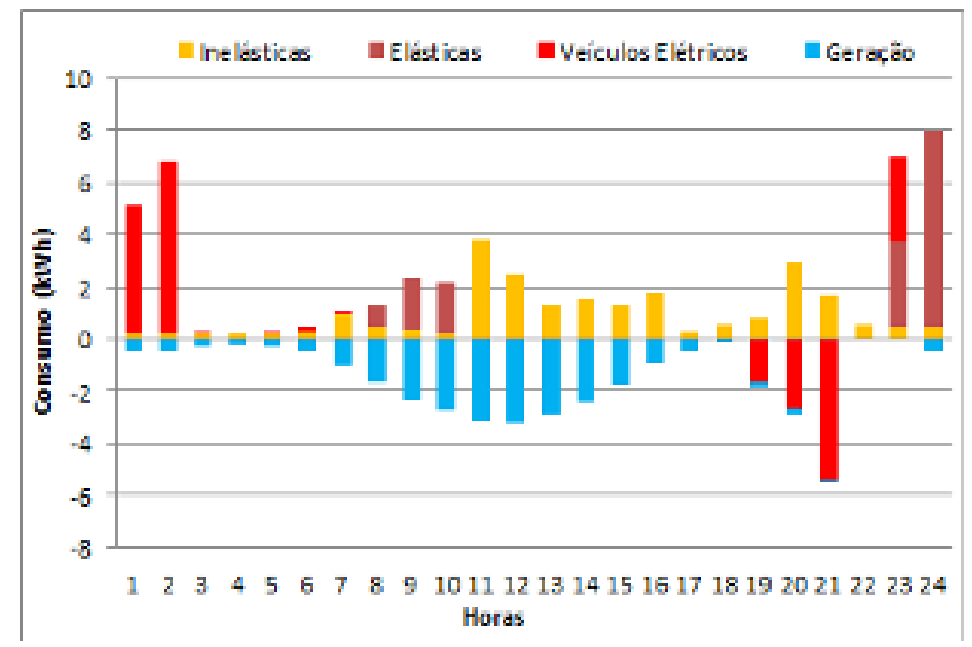

Figure 5 - Multiple generation plus consumption redistribution. Source: The authors.

In a fourth and last scenario, the impact of adding other storage devices (batteries) to the residence is evaluated, in order to dispatch the surplus to the concessionaire as well as to provide local storage of energy, associated with the available storage in the electric vehicle. This result is presented in Figure 6, showing only the complete system scenario, that is, redistribution of loads, inclusion of wind and solar generation, electric vehicle and storage device.

It is worth noticing that as it deals with hourly charging, only the inclusion of storage system would also be able to reduce the value of the invoice, storing the energy acquired at times of low value and dispatch at times of high cost. However, this only is valid if the cost of maintaining and acquiring the storage system is less than the gain provided by that operation.

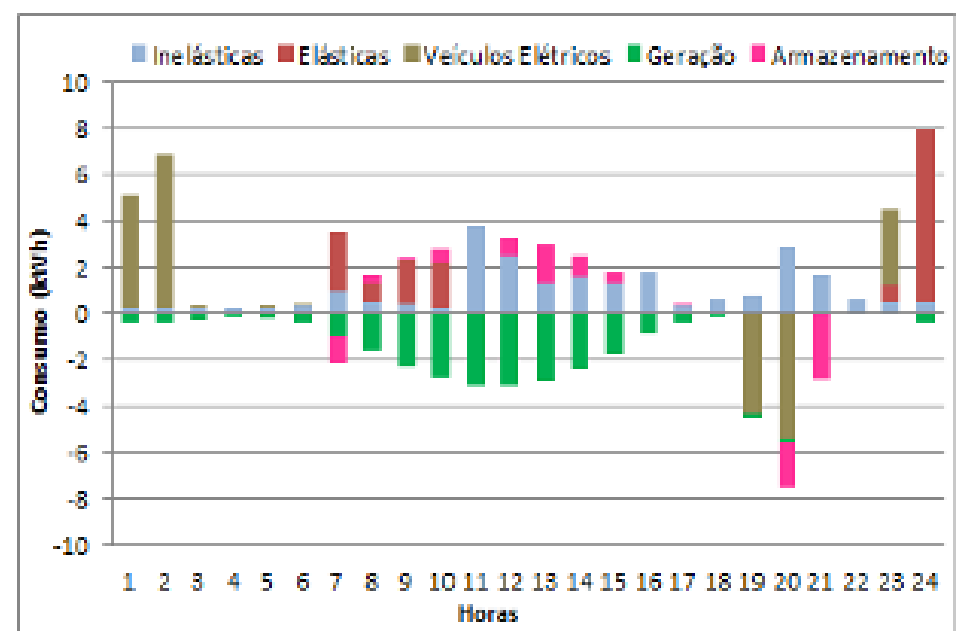

Figure 6 - Multiple generation, storage, electric vehicle and redistribution of consumption. Source: The authors.

Table 1 summarizes the results obtained, which take into account the simulated consumption and the values obtained from ANEEL [7][8] for customers connected to Copel at a white hourly rate [8]. In the modeling, it is considered that the consumer receives - for the $\mathrm{kWh}$ delivered to the concessionaire - $80 \%$ of the value that he pays for the $\mathrm{kWh}$ consumed by the concessionaire. 
Table 1- Results of the various sceneries.

\begin{tabular}{lccc}
\multirow{2}{*}{\multicolumn{1}{c}{ Scenario }} & \multicolumn{3}{c}{ Consumption (R\$) } \\
\cline { 2 - 4 } & Day & \multicolumn{1}{c}{ Month } & \multicolumn{1}{c}{ Year } \\
\hline Base & 56.73 & 1701.81 & 20705.42 \\
\hline Redistribution & 22.84 & 685.18 & 8336.36 \\
\hline Case 1 & 11.33 & 339.90 & 4135.44 \\
\hline Case 2 & 20.98 & 629.39 & 7657.59 \\
\hline Case 3 & 8.88 & 266.47 & 3242.09 \\
\hline Case 4 & 5.98 & 179.51 & 2184.03 \\
& \multicolumn{3}{c}{ Source: The authors. }
\end{tabular}

It is observed, as initially stated, that only the adoption of a system of loads redistribution in time is already capable of promoting a significant reduction in the value of the invoice, something close to $60 \%$. Cases 1,2 and 3 vary only in the amount of energy generated and the time that this happens, which justifies the hypothesis that the installed generation capacity is closely linked to the economy.

Finally, case 4, in which the storage system is included, compared to case 3 , which is actually the same situation without the use of a storage system, shows an overall reduction of over $90 \%$ in the invoice, On the other hand, if we compare only the two scenarios 3 and 4, in absolute terms, there is a reduction of almost $34 \%$ in the amount spent.

That is to say, the economy in the various scenarios is closely linked to the installed generation capacity and to the characteristics of the storage systems, and can even reach a positive balance, in order to market part of the excess generated power with the concessionaire. The possibility of selling the excess and not only the credit, as provided by ANEEL's regulatory resolution No. 482/2012, has been adopted in the modelling.

It is worth noting that in all the analyzed scenarios there was no reduction in consumption, the work performed was the same, simply redistributing consumption over time, adding energy storage and also local generation from diverse energy matrices.

\section{CONCLUSION}

Given the diverse possibilities of electricity generation that emerge on the world stage, generation from renewable sources in small plants, or microgeneration, is each day more feasible and easily accessible.

In this research, in turn, it was possible to improve a distribution model of variable loads in facilities where distributed generation is present. This model consists of the application of optimization algorithms, in a Mixed Interactive Linear Programming (MILP) problem.

Eventually, it was observed that the developed algorithm presents the expected performance, and it can be applied to other classes and dimensions of loads and installations, simultaneously. Yet, as a result of the application of the algorithm, a possible reduction in the monetary value of an account due to the redistribution of loads over time, considering a white hourly load, has been observed.

The algorithm was useful for reducing costs, even in case of using the white tariff, for situations where there is no generation, but there is storage and the possibility of redistribution of loads during the day.

Thus, considering the possibility of energy trade with the concessionaire and the hourly rate variation, based on previous studies found in the literature, an algorithm 
capable of proposing a better time distribution of the loads over time has been improved and tested in order to obtain the lowest cost of energy acquisition, considering the presence of wind, solar, electric vehicle and storage systems. In this last scenario, and with greater impact, reaching an economy close to $90 \%$.

Future work may include a more in-depth evaluation of commercial modeling software from renewable sources or not, and the development of plug-ins for them, the improvement of the simulation model of the generation result developed, considering other variables that can impact the final result and also improvements in the algorithm of temporal distribution of load, that was adjusted, in a way to facilitate its use, to have more reliable results, to consider the possibility of payment of taxes in the transaction and also the modality of energetic credits, without financial return.

Still, if possible, integrate some software or algorithm capable of automatically create the curves of generation of the renewable sources from the environmental data and the yield of the equipment.

\section{REFERENCES}

1. H. S. Santos, C. Unsihuay-Vila. "Modelo computacional para alocação ótima integrada de cargas, veículo elétrico e armazenamento de energia em uma microrrede residencial, considerando uma microgeração solar”, SmartEnergy - Conferência internacional das redes inteligentes. Curitiba, 2016.

2. Moraes, R. A. Estudo da viabilidade técnica e econômica da inserção da microgeração eólica: Estudo de caso prédio de engenharia elétrica da Universidade Federal do Paraná. 2013, Graduation project in Electrical Engineering - Universidade Federal do Paraná, Curitiba, 2013

3. Onar, O. C.; Uzunoglu, M.; Alam, M. S. Dynamic Modeling, design and simulation of a wind/fuel cell/ultra-capacitor-based hybrid power generation system. Science Direct. $\mathrm{N}^{\circ} 161$, 18 May 2006.

4. Matos, Mariana Brito de. Análise Energética de um Sistema Híbrido Eólico-Fotovoltaico com Armazenamento de Energia Elétrica através do Hidrogênio e Banco de Baterias. 2013, Doctoral tesis in planning of energy systems - Universidade Estadual de Campinas, Campinas, 2013

5. Hauschild, Luciano; Avaliação de Estratégias de Operação de Sistemas Híbridos Fotovoltaico-Eolico-Diesel. 2006, Master dissertation in energy - Universidade de São Paulo, São Paulo, 2006.

6. Debastiani, Gilson. Avaliação da eficiência energética de um sistema híbrido eólicofotovoltaico para cascavel-paraná. 2013, Master dissertation in energy in agriculture Universidade Estadual do Oeste do Paraná, Cascavel, 2013.

7. Agência Nacional de Energia Elétrica (ANEEL). Resolução homologatória no 2.096, 21 Jun 2016. Disponible in: <http://www2.aneel.gov.br/cedoc/reh20162096ti.pdf>. Acess in: 08 Aug 2016.

8. Companhia Paranaense de Energia (COPEL). Tarifa Convencional - subgrupo B1. Disponible

<http://www.copel.com/hpcopel/root/nivel2.jsp?endereco=\%2Fhpcopel\%2Froot\%2Fpagcopel2 .nsf\%2F5d546c6fdeabc9a1032571000064b22e\%2Fe3a5cb971ca23bf503257488005939ba>.

Acess in: 08 Aug 2016. 